\title{
Multiscale Retinex Application to Analyze Face Recognition
}

\author{
Suprihanto Suprihanto ${ }^{1}$, Maisevli Harika ${ }^{2}$, Maya Sri Ramadiani ${ }^{3}$, Diena Rauda Ramdania ${ }^{4}$ \\ 1,2,3 Department of Computer and Informatics Engineering, Politeknik Negeri Bandung, Indonesia \\ ${ }^{2}$ Computer Vision and Artificial Intelligence Lab, Pukyong National University, Busan, South Korea \\ ${ }^{4}$ Department of Informatics, UIN Sunan Gunung Djati Bandung, Indonesia
}

\section{Article Info}

Article history:

Received December 01, 2020

Revised December 03, 2020

Accepted December 08, 2020

Published December 30, 2020

\section{Keywords:}

Face recognition

Illumination

Multiscale retinex

Principal component analysis

Variations

\begin{abstract}
The main challenge that facial recognition introduces is the difficulty of uneven lighting or dark tendencies. The image is poorly lit, which makes it difficult for the system to perform facial recognition. This study aims to normalize the lighting in the image using the Multiscale Retinex method. This method is applied to a face recognition system based on Principal Component Analysis to determine whether this method effectively improves images with uneven lighting. The results showed that the Multiscale Retinex approach to face recognition's correctness was better, from $40 \%$ to $76 \%$. Multiscale Retinex has the advantage of dark facial image types because it produces a brighter image output.
\end{abstract}

\section{Corresponding Author:}

Maisevli Harika,

Department of Computer and Informatics Engineering, Politeknik Negeri Bandung, Indonesia

Jl. Gegerkalong Hilir, Ciwaruga, Kec. Parongpong, West Bandung District, West Java 40559

Email: maisevli@polban.ac.id

\section{INTRODUCTION}

Biometric technology has made many advances. Biometric technology is a technology that utilizes individual physiological identities. One of the purposes of using biometric technology is to obtain a person's identity, such as fingerprints, eyes, voice, or face [1]. Facial recognition is a biometric technology used to identify a person's identity based on a feature on the face to differentiate between individuals.

Face recognition systems are now increasingly being found in people's lives. One application of face recognition can be found in making National Identity Cards (KTP) and Passport [2]. There are two critical elements in the facial recognition system, namely, face detection and recognition processes. In the face detection process, the presence of a face in the input image can be found, making it easier for the next process, namely face recognition.

This research will use the face detection method using Viola-Jones. The Viola-Jones method has an algorithm to detect each pixel from the input image into a face or not. After the face has been successfully detected, it will then be saved and given an identity. There are many techniques for performing facial recognition; Principal Component Analysis (PCA). PCA is used because it can reduce an object's dimensions and take essential characteristics of the object being processed. Therefore, the system will be recognized through PCA calculations' characteristics or features on the object.

Several previous studies have successfully implemented the PCA algorithm for object recognition, including vehicle number plate detection [3], NTT woven cloth motif [4], signature identification [5], signature pattern [6], group facial recognition [7], and 3-dimensional facial recognition [8]. The accuracy rate resulting from the PCA method for facial recognition is also relatively high, ranging from 80\% -90\% [7]-[9].

Even though the facial recognition system has reached the application development stage, the face recognition system cannot be said to have run entirely. There are still many weaknesses that still need to be investigated. One of the problems that are still open to research is facial recognition with shooting situations that are not well-conditioned. Not well conditions happened because, in general, face recognition systems require taking facial images from a well-conditioned condition. The face image is taken in a closed space with 
even lighting. The face is facing the camera and a reasonably close distance from the camera. One of the problems faced by facial recognition in conditions that are not well conditioned is uneven lighting or dark [light, greetings]. The low lighting in Figure 1 is due to one of the reasons for taking images from a distance in an open space. Figure 1 Shows facial images from the Yale B database with changes in lighting caused by a light source at a specific position, which will give a significant difference.

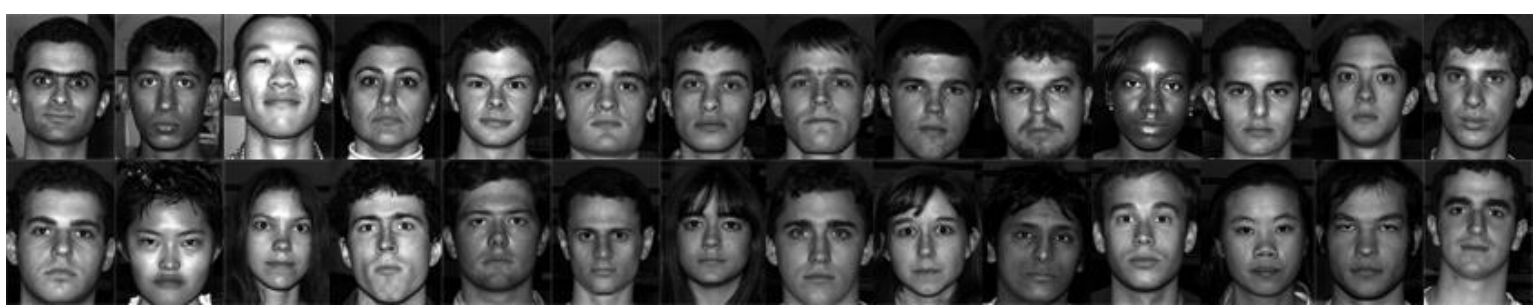

Figure 1. The same face images at different exposures [10]

The lighting handling processes critical in Figure 1, it is necessary to have a method or approach that can improve image quality, especially in lighting normalization. Later, it can be used to help improve the accuracy of facial recognition systems. One of the methods that can normalize the lighting on the image is Multiscale Retinex. The advantage of the Multiscale Retinex method is that it can improve image quality by increasing the original color and brightness of the input image, especially when taking images in dark conditions [11].

\section{METHODOLOGY}

Multi-Scale Retinex (MSR) is a further development of the Single Scale Retinex method. Multiscale Retinex is probably the most successful center-surround image filter [12]. Several previous studies have used this method for image enhancement [11], [13]-[16], and video enhancement [17], [18] with several additional filters and other algorithms. The MSR method can also improve color in images [19]-[23], low illumination [24], [25], etcetera.

Different scales are used and given different weights to combine the advantages and eliminate the disadvantages of low and large scales. Here is the MSR formula [26]:

$$
R_{m s r_{i}}=\sum_{n=1}^{N} W_{n} R_{n_{i}}
$$

$R_{m s r_{i}}$ is the MSR output, which is the sum of the weighted SSR outputs. $\mathrm{N}$ is the number of scales used. $W_{n}$ is the weight associated with the nth scale. $R_{n_{i}}$ is the output of SSR socialized with the nth scale.

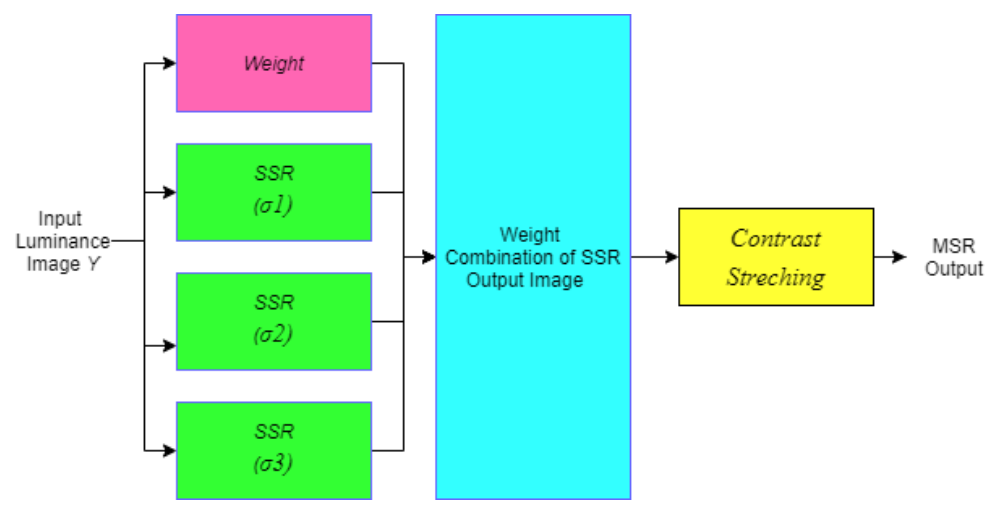

Figure 2. Multiscale Retinex [27]

The type of research that will be used is using quantitative research methods with experimental research techniques. This study will test the lighting normalization method with Multiscale Retinex as an image improvement process before its facial recognition process. In this study, we will look for the effect of using variations in the facial image lighting used on facial recognition accuracy. In this study, the independent variable is the data set used, which includes the direction of the light source received by the face object in the image. At the same time, the dependent variable is the accuracy of facial recognition. The relationship between 
the independent variable face types and different light sources' direction affects facial recognition accuracy. Namely, the poor lighting conditions on a face object will cause the possibility of an identity error when the system carries out facial recognition.

The object used in this study is a sample image contained in the face data of the Yale B Face Database [10]. The facial data is assumed to have been captured following the ISO / IEC 19794-5 standard. Each face data has a standard for facial recognition, which has an essential part in the composition of a face (eyes, nose, and mouth), facing straight ahead with different light sources and a full face.

Data preparation is done by collecting data and selecting data to be used in conducting experiments. Data collection aims to collect the required data. This study's training data amounted to 50 images, and the test images used were 25 data. The comparison of training data and test data is $\frac{2}{3}: \frac{1}{3}$.

In this study, not all facial images were used. The face image used as training data is frontal (taken from the front) with illumination conditions from a point light source in a normal position. The test data is a frontal face image with illumination conditions from a point light source with a position varying from -1300 to 1300 horizontally (azimuth) and -400 to 400 vertically (elevation). Each image in the face database already has the subject's identity in the image [5]. The entire face image is manually flattened, cropped, and resized to 100x100 pixels. Figure 3 depicts the same image with different light levels.
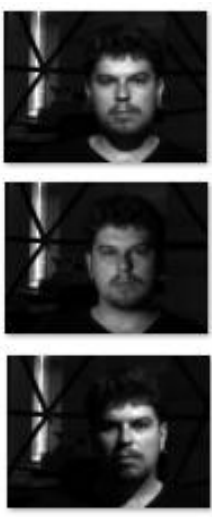
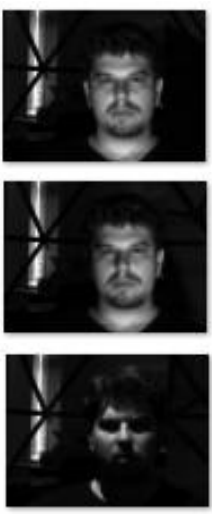

Figure 3. An example of a face image of a subject
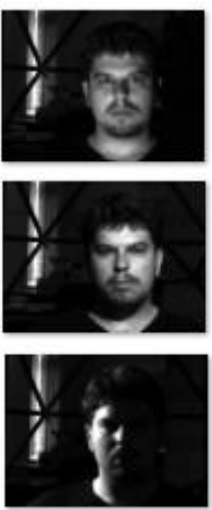
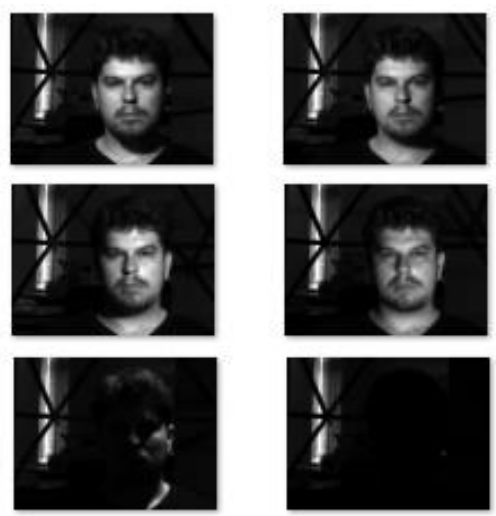

In this study, the experimental process is divided into three parts: the first scenario for the experiment without applying the normalization method of lighting so that the facial image will be detected and recognized by the system. The second is experimenting by normalizing the facial image before the detection and face recognition process is carried out. Multiscale Retinex method and the third is by separating the face image if the image is light, the normalization process will not be carried out. In contrast, for dark images, the normalization process will be carried out. The test image separation is carried out based on the average pixel intensity value in the experimental results of scenarios one and two. Data testing scenarios are depicted in Figures 4, 5, and 6.

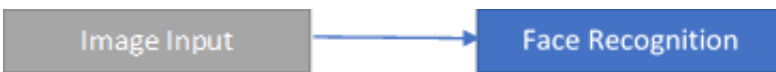

Figure 4. First Scenario

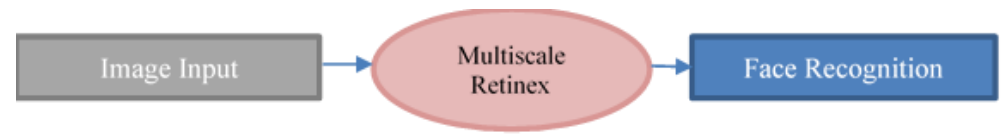

Figure 5. Second Scenario

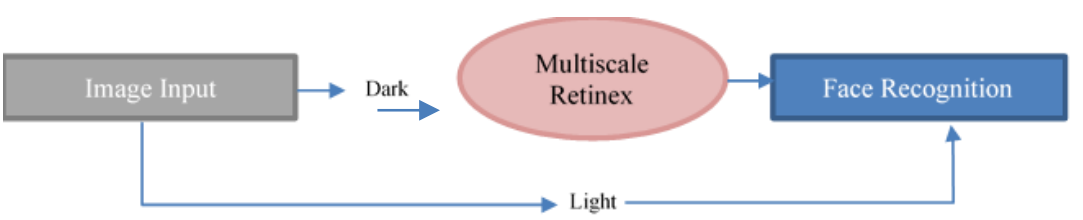

Figure 6. Third Scenario

As data for training, five subjects were prepared, with each subject having ten images so that a total of 50 facial images were used in the training process. The image used for training is a standard image with reasonably even lighting. The test data for the five subjects also came from the same data set. However, this 
time even was lighting chosen. Instead, it used several images with five different lighting conditions (conditions 1, 2, 3, 4, and 5 in Figure 7) so that there were 25 images to be tested. The indicators seen to perform analysis in each test scenario are the percentage of success (accuracy) in facial recognition.

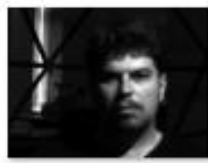

(1)

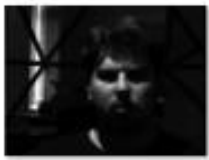

(2)

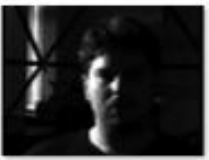

(3)

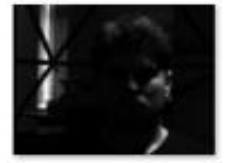

(4)

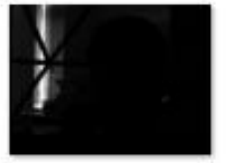

(5)

Figure 7. Data training from one person

\section{RESULT AND DISCUSSION}

\subsection{Result}

In the first scenario, the facial image will be tested directly on the facial recognition system. Whereas in the second scenario, the facial image will be normalized first before being recognized in the face recognition system (Table 1).

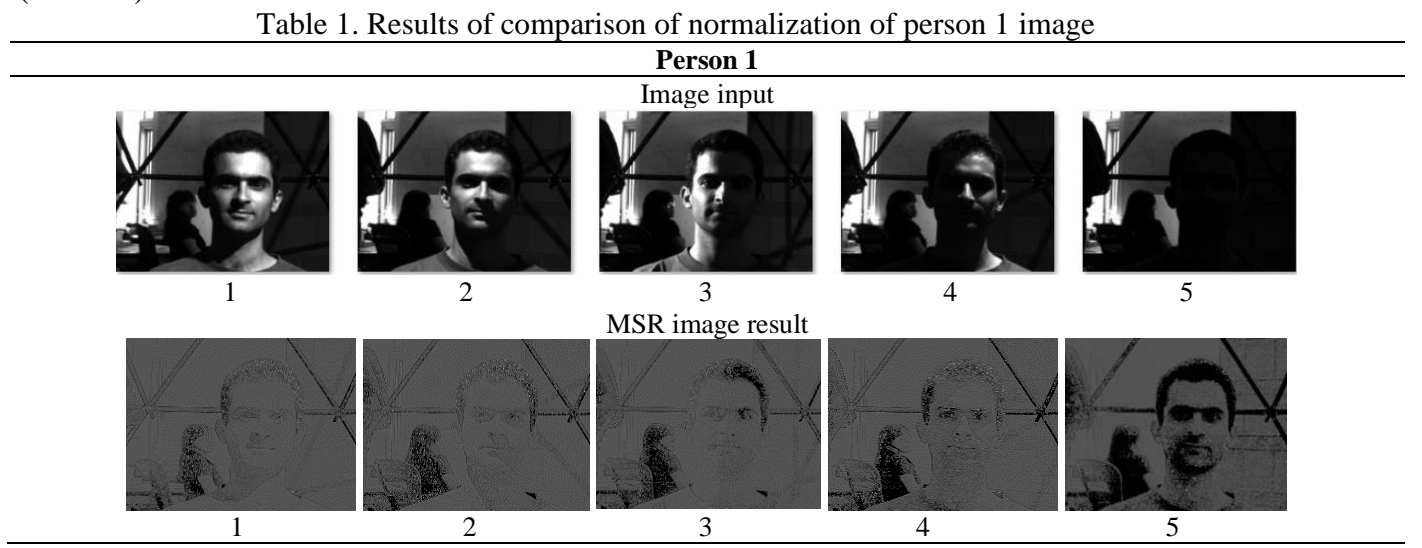

Table 2. Person 1 Experimental results

\begin{tabular}{|c|c|c|c|c|c|}
\hline No & $\begin{array}{c}\text { Name of Image } \\
\text { Test }\end{array}$ & $\begin{array}{c}\text { Face Detection without } \\
\text { MSR Normalization }\end{array}$ & Recognized as & $\begin{array}{l}\text { Face Detection with } \\
\text { MSR Normalization }\end{array}$ & Recognized as \\
\hline 2 & Person 1 & Detected & Person 1 & Detected & Person 3 \\
\hline 4 & Person 1 & Undetected & - & Detected & Person 1 \\
\hline 5 & Person 1 & Undetected & - & Detected & Person 1 \\
\hline \multicolumn{3}{|c|}{ Accuracy } & $(2 / 5) * 100=40 \%$ & \multicolumn{2}{|c|}{$80 \%$} \\
\hline
\end{tabular}

Table 3. Comparison results of person 2 image normalization
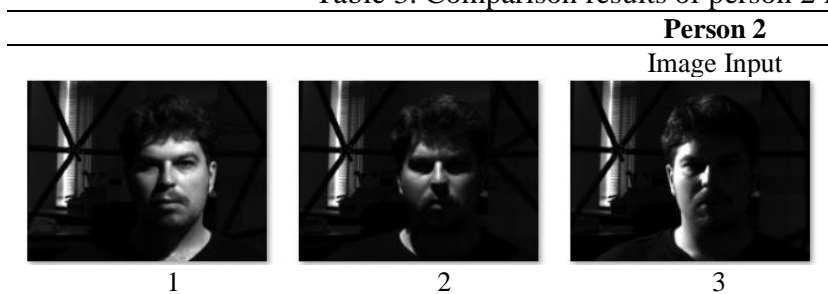

3

MSR Image Result

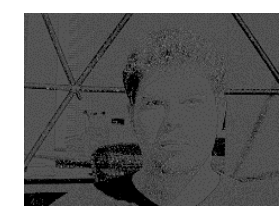

1
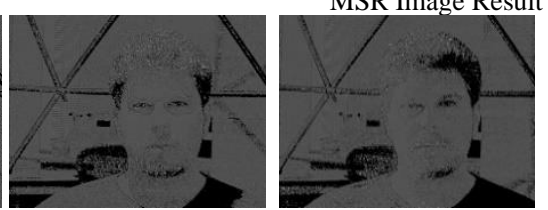
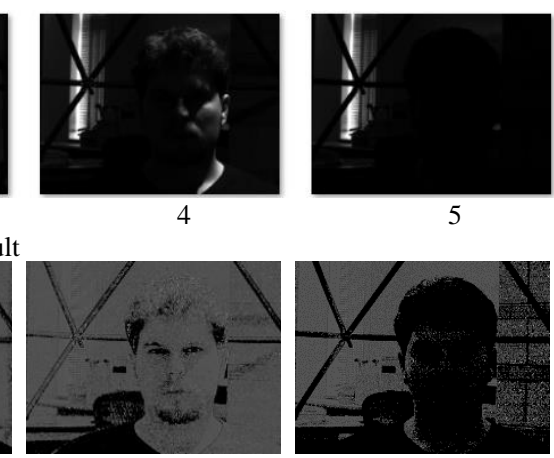

5

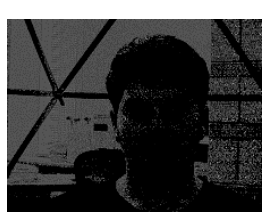

5

Table 4. Person 2 Experimental results 


\begin{tabular}{|c|c|c|c|c|c|}
\hline No & $\begin{array}{c}\text { Name of Image } \\
\text { Test }\end{array}$ & $\begin{array}{l}\text { Face Detection without } \\
\text { MSR Normalization }\end{array}$ & Recognized as & $\begin{array}{c}\text { Face Detection } \\
\text { with MSR } \\
\text { Normalization }\end{array}$ & Recognized as \\
\hline 1 & Person 2 & Detected & Person 2 & Detected & Person 2 \\
\hline 2 & Person 2 & Detected & Person 2 & Detected & Person 2 \\
\hline 3 & Person 2 & Undetected & - & Detected & Person 2 \\
\hline 4 & Person 2 & Undetected & - & Detected & Person 2 \\
\hline 5 & Person 2 & Undetected & - & Undetected & - \\
\hline \multicolumn{3}{|c|}{ Accuracy } & $40 \%$ & \multicolumn{2}{|c|}{$80 \%$} \\
\hline
\end{tabular}

Table 5. Comparison results of person 3 image normalization

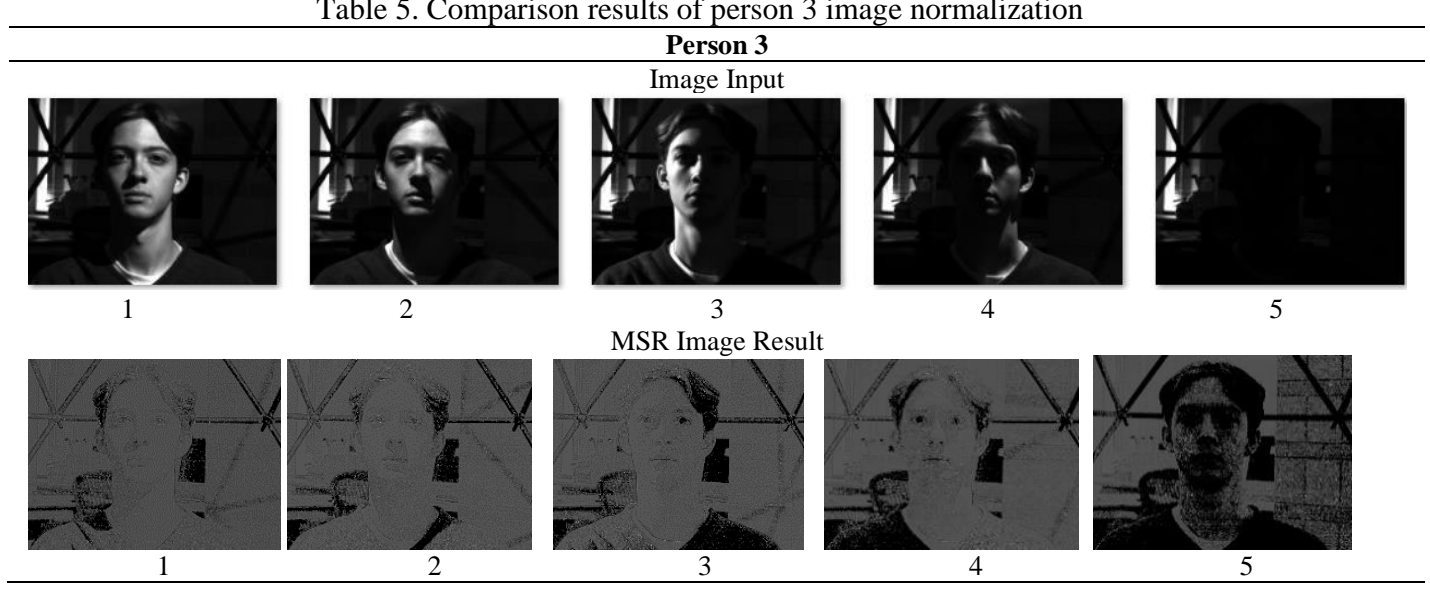

Table 6. Person 3 Experimental results

\begin{tabular}{|c|c|c|c|c|c|}
\hline No & $\begin{array}{c}\text { Name of Image } \\
\text { Test }\end{array}$ & $\begin{array}{c}\text { Face Detection without } \\
\text { MSR Normalization }\end{array}$ & Recognized as & $\begin{array}{l}\text { Face Detection } \\
\text { with MSR } \\
\text { Normalization }\end{array}$ & Recognized as \\
\hline 1 & Person 3 & Detected & Person 3 & Detected & Person 3 \\
\hline 2 & Person 3 & Detected & Person 3 & Detected & Person 3 \\
\hline 3 & Person 3 & Undetected & - & Detected & Person 3 \\
\hline 4 & Person 3 & Undetected & - & Detected & Person 3 \\
\hline 5 & Person 3 & Detected & - & Detected & - \\
\hline \multicolumn{3}{|c|}{ Accuracy } & $40 \%$ & \multicolumn{2}{|c|}{$80 \%$} \\
\hline
\end{tabular}

Table 7. Comparison results of person 4 image normalization

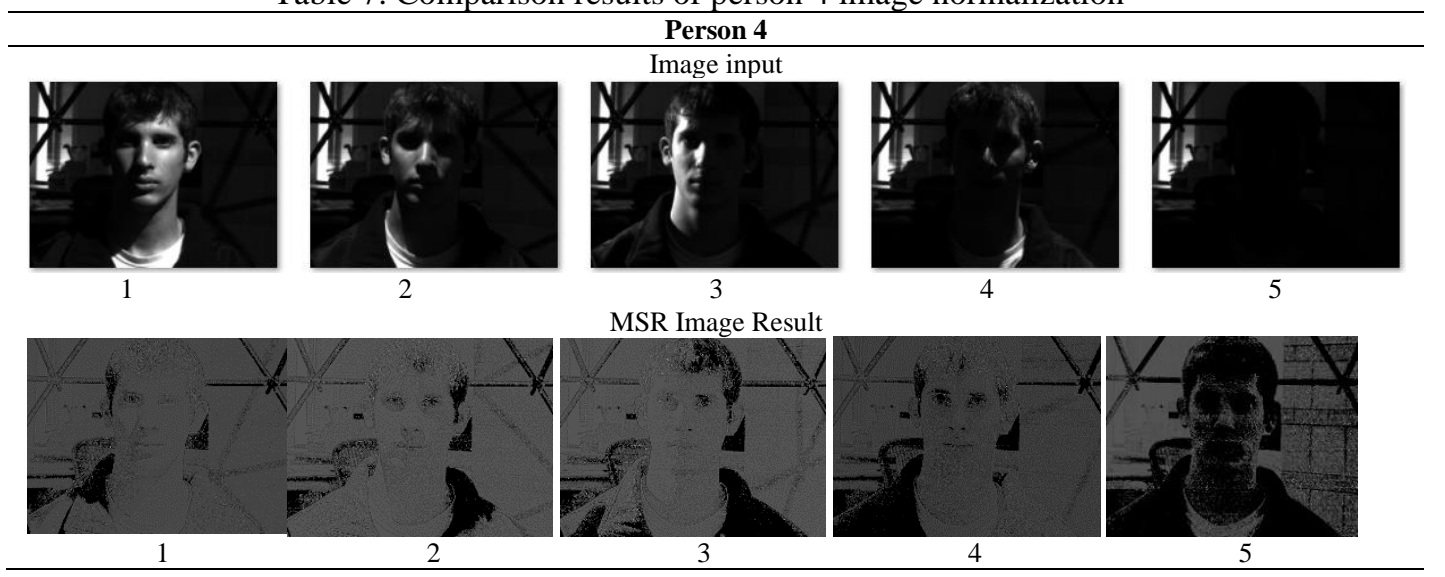

Table 8. Person 4 Experimental results

\begin{tabular}{|c|c|c|c|c|c|}
\hline No & $\begin{array}{c}\text { Name of Image } \\
\text { Test }\end{array}$ & $\begin{array}{l}\text { Face Detection without } \\
\text { MSR Normalization }\end{array}$ & Recognized as & $\begin{array}{c}\text { Face Detection } \\
\text { with MSR } \\
\text { Normalization } \\
\end{array}$ & Recognized as \\
\hline 1 & Person 4 & Detected & Person 4 & Detected & Person 4 \\
\hline 2 & Person 4 & Detected & Person 4 & Detected & Person 4 \\
\hline 3 & Person 4 & Undetected & - & Undetected & - \\
\hline 4 & Person 4 & Undetected & - & Undetected & - \\
\hline 5 & Person 4 & Undetected & - & Detected & - \\
\hline \multicolumn{3}{|c|}{ Accuracy } & $40 \%$ & \multicolumn{2}{|c|}{$40 \%$} \\
\hline
\end{tabular}




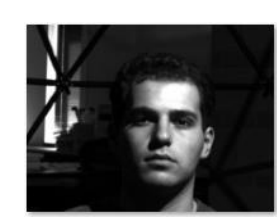

1

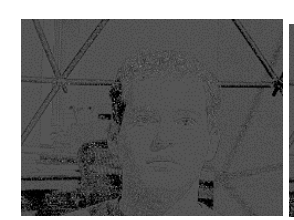

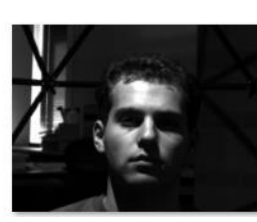

2

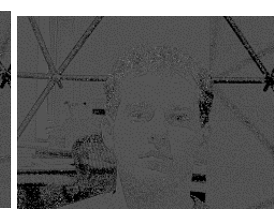

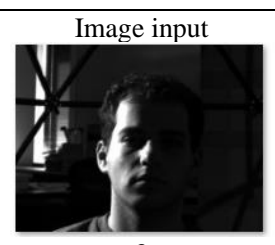

3

MSR image result

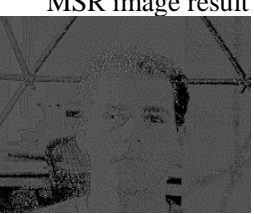

3

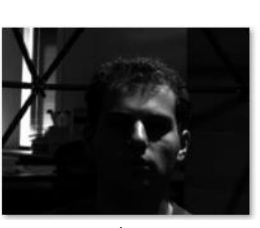

4

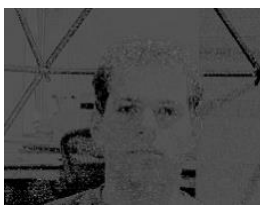

4

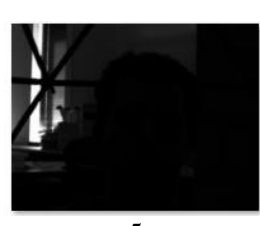

5

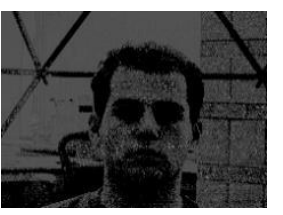

Table 10. Person 5 Experimental results

\begin{tabular}{|c|c|c|c|c|c|}
\hline No & $\begin{array}{c}\text { Name of Image } \\
\text { Test }\end{array}$ & $\begin{array}{l}\text { Face Detection without } \\
\text { MSR Normalization }\end{array}$ & Recognized as & $\begin{array}{c}\text { Face Detection } \\
\text { with MSR } \\
\text { Normalization }\end{array}$ & Recognized as \\
\hline 1 & Person 5 & Detected & Person 5 & Detected & Person 5 \\
\hline 3 & Person 5 & Undetected & - & Detected & Person 5 \\
\hline 4 & Person 5 & Undetected & - & Detected & Person 5 \\
\hline 5 & Person 5 & Undetected & - & Detected & - \\
\hline
\end{tabular}

Based on the third experimental scenario (Figure 6), a separation of the test images already light and dark are carried out. In the image with lighting conditions 1 , condition 2 , and condition 3 , the image will be immediately recognized without going through the Multiscale Retinex normalization process. In contrast, in the image with condition 4 and condition 5 in the image that tends to be dark, the Multiscale Retinex normalization process will be performed before the face recognition process is carried out.

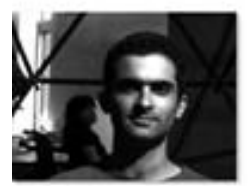

1st condition

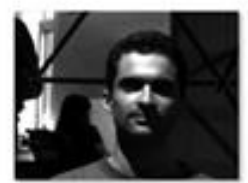

2nd condition

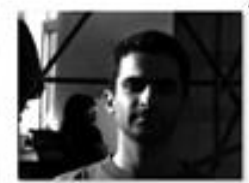

3rd condition

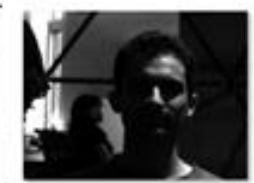

4th condition

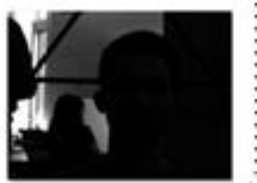

5th condition

Figure 7. Lighting conditions in person 1

The division of light and dark images is based on calculating the average value, which is the intensity of each test image's pixels. The testing phase was carried out using five subjects, consisting of five different lighting conditions. Figure 7 (conditions 1-5) so that there were a total of 25 test data. Table 11 shows the results of the average value of pixel intensity in each test image shown in Table 11. The process of calculating the average value of each image pixel is carried out with the Matlab2019 program.

Table 11. Average pixel intensity values

\begin{tabular}{lccccc}
\hline & $\begin{array}{c}\text { 1st condition } \\
\text { image }\end{array}$ & $\begin{array}{c}\text { 2nd condition } \\
\text { image }\end{array}$ & $\begin{array}{c}\text { 3rd condition } \\
\text { image }\end{array}$ & $\begin{array}{c}\text { 4th condition } \\
\text { image }\end{array}$ & $\begin{array}{c}\text { 5th condition } \\
\text { image }\end{array}$ \\
\hline Person 1 & 31.5938 & 25.3035 & 26.0314 & 21.6873 & 14.6617 \\
Person 2 & 30.5691 & 20.6134 & 24.0446 & 16.9153 & 10.1010 \\
Person 3 & 35.9389 & 28.5522 & 27.8294 & 19.5954 & 10.0197 \\
Person 4 & 35.0493 & 24.3594 & 25.6534 & 18.5483 & 10.2237 \\
Person 5 & 41.0301 & 36.3389 & 33.8164 & 25.2287 & 14.9142 \\
\hline Average & $\mathbf{3 4 . 8 3 6 2 4}$ & $\mathbf{2 7 . 0 3 3 4 8}$ & $\mathbf{2 7 . 4 7 5 0 4}$ & $\mathbf{2 0 . 3 9 5}$ & $\mathbf{1 1 . 9 8 4 0 6}$ \\
\hline
\end{tabular}

Based on the experimental results in scenario 3, the Multiscale Retinex normalization process is suitable for images with an average pixel intensity value starting from 0-27 and for an image that is already bright. In this case, it has an average pixel intensity value of 27-35 and above that is not. It is necessary to do the normalization process because the accuracy results given are following the experiment. It can be seen that 
the higher the average value in the image, the higher the brightness. Tabel 12 is the level of accuracy of the experimental results based on scenario 3 .

Table 12. The accuracy level of Person 1 - Person 5

\begin{tabular}{ccc}
\hline No & Name of data & Accuracy \\
\hline 1 & Person 1 & $100 \%$ \\
2 & Person 2 & $80 \%$ \\
3 & Person 3 & $80 \%$ \\
4 & Person 4 & $40 \%$ \\
5 & Person 5 & $80 \%$ \\
\hline
\end{tabular}

\subsection{Discussion}

Based on the results of experiments conducted for facial recognition, it can be seen that the type of lighting influences the accuracy of the system in identifying faces in the face image. Suppose the test image has sufficiently varied lighting conditions or tends to be dark. It can cause the system to be challenging to identify the face, so the face recognition process cannot be done optimally. Experimental results were obtained for facial recognition on the Yale B dataset based on the experimental scenario. The results show in Figure 8.

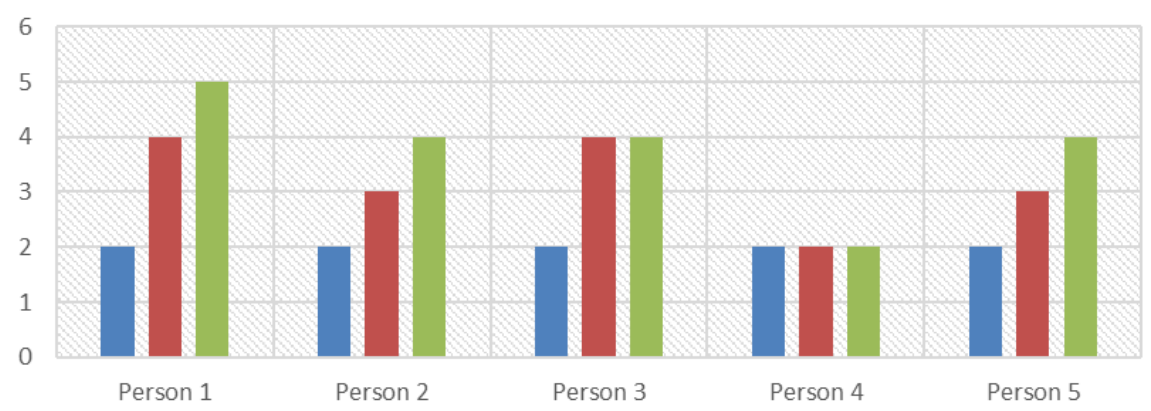

Description: Blue: Without Multiscale Retinex (Scenario 1), Red: With Multiscale Retinex (Scenario 2), Green: Join method (Scenario 3).

Figure 8. Diagram of the experiment result

Figure 8 shows a graph of the accuracy of the facial recognition experiment results with input images in images without normalization, with Multiscale Retinex normalization, and join method. Conditions 1, 2, and 3 were not normalized, while conditions 4 and 5 were normalized. Table 13 shows that with the method's application, Normalization of the Multiscale Retinex can increase facial identification accuracy in images with dark light conditions. However, there is no need to do the normalization process for images with bright light conditions because it can reduce facial recognition accuracy.

Table 13. Results of Improved Face Recognition Accuracy

\begin{tabular}{ccccc}
\hline No & Data name & Without MSR & $\begin{array}{c}\text { Face Recognition Accuracy } \\
\text { Multiscale Retinex }\end{array}$ & Join Method \\
\hline 1 & Person 1 & $40 \%$ & $80 \%$ & $100 \%$ \\
2 & Person 2 & $40 \%$ & $80 \%$ & $80 \%$ \\
3 & Person 3 & $40 \%$ & $80 \%$ & $80 \%$ \\
4 & Person 4 & $40 \%$ & $40 \%$ & $40 \%$ \\
5 & Person 5 & $40 \%$ & $60 \%$ & $80 \%$ \\
\hline & Total average & $40 \%$ & $68 \%$ & $76 \%$ \\
\hline
\end{tabular}

Overall, the Multiscale Retinex normalization method in the test image with varying lighting conditions tends to be uneven, increasing facial image recognition success from $40 \%$ to $68 \%$. However, if both are done by separating the image in dark and bright lighting, it will produce better accuracy, namely $76 \%$. It can be seen that the image processing process using the Multiscale Retinex Method for test images is suitable for the type of image with lighting that tends to be dark. For images with good lighting, there is no need for the Multiscale Retinex process.

\subsection{Analysis of the Effect of Multiscale Retinex on Face Recognition}

Based on the results of experiments that have been carried out, it is known that the Multiscale Retinex has advantages in the dark type of input image. The MSR method can produce a brighter image output without changing the image's original color (see Figure 9). However, the drawback of the MSR method lies in the input 
image with relatively bright conditions. It happened because the resulting image output will be brighter and visually faded (Figure 10).
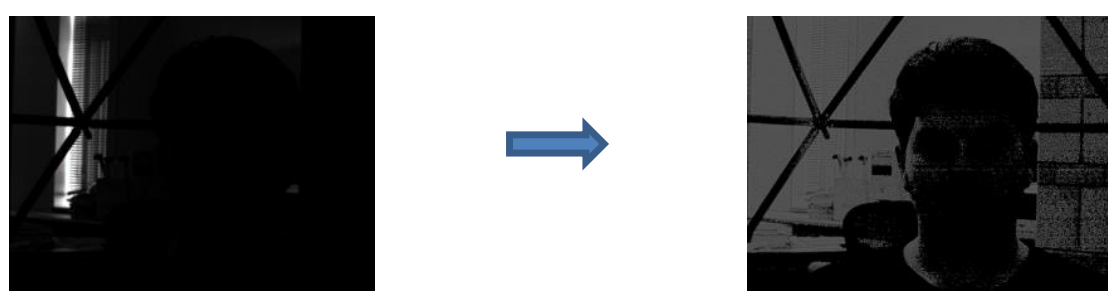

Figure 9. Multiscale Retinex results in a dark image
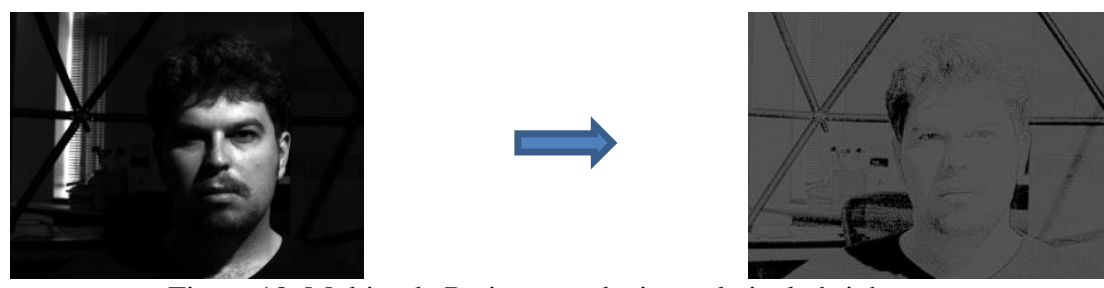

Figure 10. Multiscale Retinex results in a relatively bright one

Based on the theory in Chapter II. The scaling properties of the Multiscale Retinex are local, so the processing for each pixel only takes into account the area around the pixel in the image. The greater the parameter value in sigma, the larger the local area will be illuminated.

An image histogram is a graph that shows the distribution of the values of the pixel intensity. With the histogram, it can be seen the brightness of an image. This analysis compares the histogram from the original image with the histogram of the image from the Multiscale Retinex process. Images that have lighter or darker contrast or brightness have a narrower histogram. The histogram is visible only in some areas of the degree of gray. A right image should have a histogram that fills the gray degree area with an even distribution of each pixel intensity. The image below compares the original image histogram and the image produced by the Multiscale Retinex method.

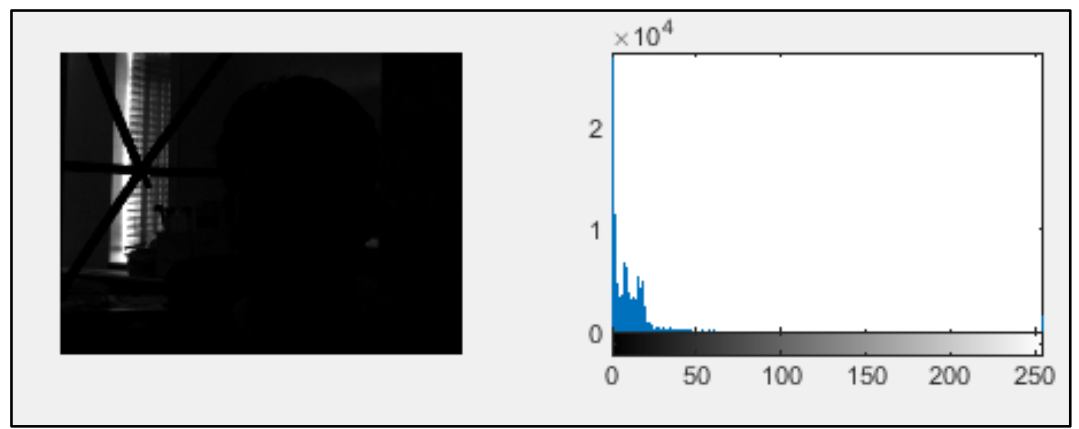

Figure 11. The results of the original image histogram

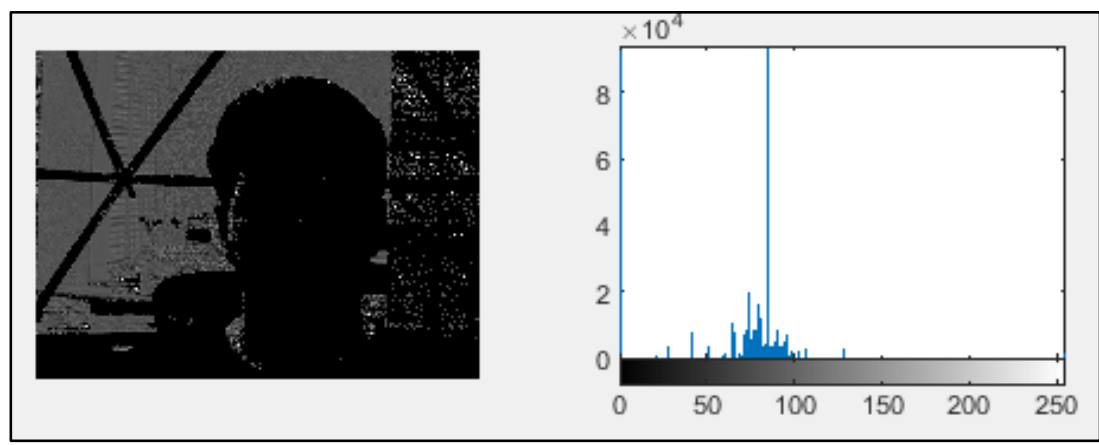

Figure 12. The results of the MSR image histogram 
The histogram stack of the original image and the image resulting from the Multiscale Retinex process shows a difference. The Multiscale Retinex image has a broader and more distributed histogram on the right. From the results of the 25 entered test images, it is found that the image histogram from the Multiscale Retinex process is better or evenly distributed when compared to the original image in poor lighting conditions or tends to be dark.

\section{CONCLUSION}

The application of the Multiscale Retinex method can properly normalize the lighting on various facial images so that the success of face detection and recognition can be increased. The greater the sigma $(\sigma)$ value used, the brighter and smoother the image will be. The experimental results show the results of the accuracy of three scenarios ranges between $40 \%-76 \%$. The type of lighting influences the success rate of face recognition. Suppose the test image has sufficient lighting conditions or tends to be dark. In that case, it can make it difficult for the system to identify the face, so the facial recognition process cannot be carried out optimally. Further research, we suggest using several faces in one image.

\section{REFERENCES}

[1] H. F. Neo, R. Devinaga, D. K. T. Yoon, and C. C. Teo, "Tourists' satisfaction in the use of biometrics technology: A conceptual paper," J. Econ. Bus. Manag., vol. 3, no. 1, pp. 98-103, 2015.

[2] SITA, "Indonesia tightens border control with SITA's extensive biometric system - International Airport Review," 2011. [Online]. Available: https://www.internationalairportreview.com/news/6835/indonesia-tightens-bordercontrol-with-sitas-extensive-biometric-system/. [Accessed: 26-Nov-2020].

[3] D. Pradika, "Implementasi Principal Component Analysis Untuk Mendeteksi Plat Nomor Kendaraan Dengan Otsu Thresholding (Implementation of Principal Component Analysis to Detect Vehicle Number Plates with Otsu Thresholding)." Universitas Pembangunan Nasional Veteran Yogyakarta, 2019.

[4] M. E. Lubis, S. Tena, and S. O. Manu, "Implementasi Principal Component Analysis (PCA) Untuk Temu Kembali Citra Motif Kain Tenun NTT Berdasarkan Warna dan Tekstur (Implementation of Principal Component Analysis (PCA) for Retrieval of NTT Woven Fabric Motif Image Based on Color and Texture)," SAINSTEK, vol. 4, no. 1, pp. 317-323, 2019.

[5] K. Alexanda, "Implementasi Algoritma Principal Component Analysis dan K-nearest Neighbor untuk Identifikasi Tanda Tangan (Implementation of Principal Component Analysis and K-nearest Neighbor Algorithms for Signature Identification).” Universitas Multimedia Nusantara, 2019.

[6] M. A. Sidik, "Sistem Deteksi Kepribadian Berdasarkan Pola Tanda Tangan Menggunakan Metode Support Vector Machine Dan Principal Component Analysis (Personality Detection System Based on Signature Pattern Using Support Vector Machine Method and Principal Component Analys.” Universitas Komputer Indonesia, 2019.

[7] M. O. H. AZMI, M. Fachrurrozi, and M. Kanda Januar, "Penerapan Metode PCA (Principal Component Analysis) Dan Euclidean Distance Untuk Pengenalan Wajah Berkelompok (Application of PCA (Principal Component Analysis) and Euclidean Distance Methods for Group Face Recognition).” Sriwijaya University, 2020.

[8] F. Taris, "Implementasi Algoritma Convolutional Neural Networks dengan Metode PCA untuk Pengenalan Wajah 3 Dimensi." Universitas Multimedia Nusantara, 2019.

[9] D. E. Pratiwi and A. Harjoko, "Implementasi Pengenalan Wajah Menggunakan PCA (Principal Component Analysis)," IJEIS (Indonesian J. Electron. Instrum. Syst., vol. 3, no. 2, pp. 175-184, 2013

[10] K.-C. Lee, J. Ho, and D. J. Kriegman, "Acquiring linear subspaces for face recognition under variable lighting," IEEE Trans. Pattern Anal. Mach. Intell., vol. 27, no. 5, pp. 684-698, 2005.

[11] D. Supriadi and P. Novantara, "Implementasi Metode Multiscale Retinex Untuk Image Enhancement Menggunakan Delphi (Implementation of the Multiscale Retinex Method for Image Enhancement Using Delphi)," NUANSA Inform., vol. 10, no. 2, 2018.

[12] A. B. Petro, C. Sbert, and J.-M. Morel, "Multiscale retinex," Image Process. Line, pp. 71-88, 2014

[13] A. S. Parihar and K. Singh, "A study on Retinex based method for image enhancement," in 2018 2nd International Conference on Inventive Systems and Control (ICISC), 2018, pp. 619-624.

[14] R. RAJIH, R. Primartha, and K. J. Miraswan, "Perbaikan Kualitas Citra Digital Menggunakan Kombinasi Adaptive Multiscale Retinex Dengan Color Restoration (Digital Image Quality Improvement Using a Combination of Adaptive Multiscale Retinex and Color Restoration)." Sriwijaya University, 2019.

[15] N. Q. Faraj and L. K. Abood, "Single Scale Retinex (SSR) and Multi Scale Retinex (MSR) Enhancement Algorithms for Thermal Night-Vision Images," Iraqi J. Sci., pp. 2486-2495, 2017.

[16] A. C. Sparavigna, "Night Image Enhancement by means of Retinex Filtering." 2020.

[17] H. Liu, X. Sun, H. Han, and W. Cao, "Low-light video image enhancement based on multiscale retinex-like algorithm," in 2016 Chinese Control and Decision Conference (CCDC), 2016, pp. 3712-3715.

[18] A. Supriyanto, "Image Enhhancement Dengan Metode Median Filter Dan Multiscale Retinex With Color Restoration Pada Dataset Video.” Universitas Komputer Indonesia, 2018.

[19] F. Matin, Y. Jeong, K. Kim, and K. Park, "Color image enhancement using multiscale Retinex based on particle swarm optimization method," in Journal of Physics: Conference Series, 2018, vol. 960, no. 1.

[20] H. Sadia, F. Azeem, H. Ullah, Z. Mahmood, S. Khattak, and G. Z. Khan, "Color Image Enhancement Using Multiscale Retinex with Guided Filter," in 2018 International Conference on Frontiers of Information Technology (FIT), 2018, pp. 82-87. 
[21] S. Bao, S. Ma, and C. Yang, "Multi-scale retinex-based contrast enhancement method for preserving the naturalness of color image," Opt. Rev., vol. 27, no. 6, pp. 475-485, 2020.

[22] M. Xue, Y. Ji, Z. Yuyan, L. Weiwei, and Z. Jiugen, "Video image dehazing algorithm based on multi-scale retinex with color restoration," in 2016 International Conference on Smart Grid and Electrical Automation (ICSGEA), 2016, pp. 195-200.

[23] P. Pandey, P. Saurabh, B. Verma, and B. Tiwari, "A multi-scale retinex with color restoration (MSR-CR) technique for skin cancer detection," in Soft Computing for Problem Solving, Springer, 2019, pp. 465-473.

[24] H. Shi et al., "Logarithmic profile mapping multi-scale Retinex for restoration of low illumination images," in Ninth International Conference on Graphic and Image Processing (ICGIP 2017), 2018, vol. 10615, p. 106152H.

[25] S. Das, M. Roy, and S. Mukhopadhyay, "Correcting Low-Illumination Images Using Multi-Scale Fusion in a Pyramidal Framework," in 2020 International Conference on Wireless Communications Signal Processing and Networking (WiSPNET), 2020, pp. 126-129.

[26] D. J. Jobson, Z. Rahman, and G. A. Woodell, "A multiscale retinex for bridging the gap between color images and the human observation of scenes," IEEE Trans. Image Process., vol. 6, no. 7, pp. 965-976, 1997.

[27] C.-H. Lee, J.-L. Shih, C.-C. Lien, and C.-C. Han, "Adaptive multiscale retinex for image contrast enhancement," in 2013 International Conference on Signal-Image Technology \& Internet-Based Systems, 2013, pp. 43-50. 